Article

\title{
Overexpression of Tamarix hispida ThTrx 5 Confers Salt Tolerance to Arabidopsis by Activating Stress Response Signals
}

\author{
Jiayu Luan, Jingxiang Dong, Xin Song, Jing Jiang and Huiyu Li * \\ State Key Laboratory of Tree Genetics and Breeding, Northeast Forestry University, Harbin 150040, China; \\ jiayuluan@126.com (J.L.); dongjingxiang@126.com (J.D.); songxinaa@126.com (X.S.); jiangjing@nefu.edu.cn (J.J.) \\ * Correspondence: lihuiyu2017@126.com
}

Received: 24 December 2019; Accepted: 7 February 2020; Published: 10 February 2020

check for updates

\begin{abstract}
Salt stress inhibits normal plant growth and development by disrupting cellular water absorption and metabolism. Therefore, understanding plant salt tolerance mechanisms should provide a theoretical basis for developing salt-resistant varieties. Here, we cloned ThTr $x$ from Tamarix hispida, a salt-resistant woody shrub, and generated ThTrx5-overexpressing transgenic Arabidopsis thaliana lines. Under $\mathrm{NaCl}$ stress, the germination rate of overexpressing ThTr $x 5$ lines was significantly increased relative to that of the nontransgenic line; under salt stress, superoxide dismutase (SOD), peroxidase (POD), catalase (CAT), and glutathione levels and root length and fresh weight values of transgenic ThTrx5 plants were significantly greater than corresponding values for wild-type plants. Moreover, with regard to the transcriptome, comparison of differential gene expression of transgenic versus nontransgenic lines at $0 \mathrm{~h}$ and $3 \mathrm{~h}$ of salt stress exposure revealed 500 and 194 differentially expressed genes (DEGs), respectively, that were mainly functionally linked to catalytic activity and binding process. Pull-down experiments showed that ThTrx bound 2-Cys peroxiredoxin BAS1-like protein that influences stress response-associated redox, hormone signal transduction, and transcription factor functions. Therefore, this work provides important insights into ThTr $x 5$ mechanisms that promote salt tolerance in plants.
\end{abstract}

Keywords: thioredoxin; salt stress; pull-down; transcription

\section{Introduction}

Thioredoxin (Trx) proteins, a class of conserved, thermostable, acidic small proteins [1] that are widely found in chloroplasts, yeast, animals, and plants [2-4], share the highly conserved active site core sequence Trp-Cys-Gly-Pro-Cys (WCXXC). Within this core sequence, two Cys residues confer unique biological properties to Trx proteins by reversibly engaging in disulfide linkage formation that releases two electrons and two protons that serve as redox pairs in various physiological reactions [5]. Based on amino acid homology, 20 Trx homologs encoded by the Arabidopsis thaliana (Hereinafter Arabidopsis) genome can be assigned to two Trx families, family I and family II. Upon structural analysis [6], family I proteins can be divided into six subclasses: $h, f, m, o, x$, and y, with Trx protein expression patterns differing among various organisms and cellular sites. For example, $m, f, x$, and $y$ subclasses are found in chloroplasts, $\mathrm{h}$ in the cytoplasm, and $\mathrm{o}$ and $\mathrm{x}$ within mitochondria. Trx-o is a newly discovered subclass of family I that has been shown to control activities of several mitochondrial proteins through sulfur bond reduction, while the organization and function of the Trx-h subfamily appears to be particularly complex. Nevertheless, most research to date has focused on Trx protein functions of $A$. thaliana and poplar (Populus spp.) models of nonwoody and woody plants, respectively.

In plants, studies investigating Trx system functions have shown that Trx proteins are mainly associated with resistance to stress, such as drought, heat, and oxidation, through the regulation 
of stress resistance genes. Notably, Trx contains cysteine residues that can participate in redox reactions catalyzed by thioredoxin reductase (TrxR), an nicotinamide adenine dinucleotide phosphate (NADPH)-dependent enzyme [7], whereby Trx, TrxR, and NADPH work together as an important thioredoxin-based antioxidant system in plants. Trx and TrxR each contain two cysteine residues located in close proximity to one another within a conserved protein core sequence. These cysteine residues can form reversible disulfide bonds that are crucially important to Trx and TrxR functions as reductants. In fact, studies have shown that this thioredoxin-based system can effectively reduce intracellular glutathione disulfide (GSSG) [8] as one of its major regulatory roles for controlling signal transduction or for maintaining cytoplasmic proteins in reduced states [9]. Moreover, this system also plays a vital role in preventing oxidative damage to nucleic acids, proteins, and cell membranes to promote survival of organisms living in aerobic environments [10]. Tamarix hispida, a deciduous shrub and an important salt-tolerant plant that thrives in high-salt environments, can form a natural forest on saline-alkali soil [11] and is an ideal species for studying plant salt tolerance mechanisms. In previous studies, nine ThTrx genes were identified through transcriptome analysis of T. hispida, three of which belong to the $m$ subclass and are localized in the chloroplast (ThTr $x 5$, $\operatorname{Th} \operatorname{Tr} x 9$, ThTrx10); four genes of m subclasses located in chloroplasts were found in the study of Arabidopsis: THIOREDOXIN M-TYPE 1 (AT1G03680.1), THIOREDOXIN M-TYPE 2 (AT4G03520.1), THIOREDOXIN M-TYPE 3 (AT2G15570), and THIOREDOXIN M-TYPE 4 (T3G15360.1) [12]. The results are shown in Figure S1. All m subclass genes contain the highly conserved WCGPC domain, and ThTr $x 5$ has the highest identity to the AtTRX-M4 (AT3G15360.1) gene in Arabidopsis. Importantly, ThTr $x 5$ has been shown to play a role in the salt stress response using real-time quantitative PCR (polymerase chain reaction)-based monitoring of T. hispida gene expression [13]. Here, the full-length sequence of the T. hispida ThTrx 5 gene was cloned into plant expression vector pGWB5 and the resulting plasmid was used to genetically transform salt-sensitive Arabidopsis. Salt tolerance effects conferred to transgenic Arabidopsis by overexpression of acquired ThTr $x 5$ were revealed by measurements of fresh weight and reduced glutathione content, while salt tolerance mechanisms were deduced from results of pull-down experiments and transcriptome analysis.

\section{Results}

\subsection{Acquisition and Salt Resistance Analysis of ThTrx5-Overexpressing Transgenic Lines}

Specific primers derived from the ThTr $x 5$ gene were designed based on T. hispida transcriptome data and were used to amplify DNA containing the predicted ThTrx 5 Open Reading Frame (ORF) sequence (length $564 \mathrm{bp}$ ) via RT-PCR to form products confirmed by DNA sequencing. Next, the ThTr $x 5$ gene was cloned into the pGWB5 vector using Gateway methodology (Figure S2). 35S is the promoter used for the expression of the gene. The resulting plasmid, 35S::ThTrx5, was transferred into Arabidopsis via the floral dipping, yielding homozygous transgenic lines that were subsequently propagated to the T3 generation. After rescreening to identify correctly constructed lines, four of these lines were designated as OE1-OE4. OE1 and OE2 exhibited highest levels of ThTr $x 5$ gene expression and thus were selected for subsequent experiments (Figure S3).

Transgenic and wild-type Arabidopsis seeds were sown onto solid medium containing different concentrations of $\mathrm{NaCl}$ for use in preliminary analysis of salt tolerance through the monitoring of germination rate. The results showed that after exposure to $100 \mathrm{mM} \mathrm{NaCl}$, the WT seed germination rate was $33 \%$ and the average germination rate of transgenic seeds (OE1, OE2) was $98 \%$. When the $\mathrm{NaCl}$ concentration was increased to $150 \mathrm{mM}$, the germination rate of WT seeds was $13 \%$ and the average germination rate of transgenic seeds (OE1, OE2) was 93\% (Figure 1). After transgenic and WT seedlings at $7 \mathrm{~d}$ post-germination were treated with $150 \mathrm{mM} \mathrm{NaCl}$ for $48 \mathrm{~h}$, they were phenotypically compared, revealing that leaves of WT plants were obviously chlorotic and yellow, while most plants of OE1/OE2 lines grew normally (Figure 2A). Chlorophyll measurement results showed significantly reduced chlorophyll content levels for both WT and transgenic lines, but chlorophyll levels in transgenic lines 
were significantly higher than WT control levels after $\mathrm{NaCl}$ stress exposure. Moreover, root lengths and fresh weights of OE1 and OE2 plants were greater than respective values for WT plants (Figure 1). When SOD (superoxide dismutase), POD (peroxidase), CAT (catalase), and glutathione (GSSG) levels in transgenic and WT plants were measured at $0 \mathrm{~h}$ and $48 \mathrm{~h}$ of stress exposure, the results revealed that expression levels of enzymes and glutathione in transgenic line plants were significantly greater than respective levels in WT plants (Figure 2).

A

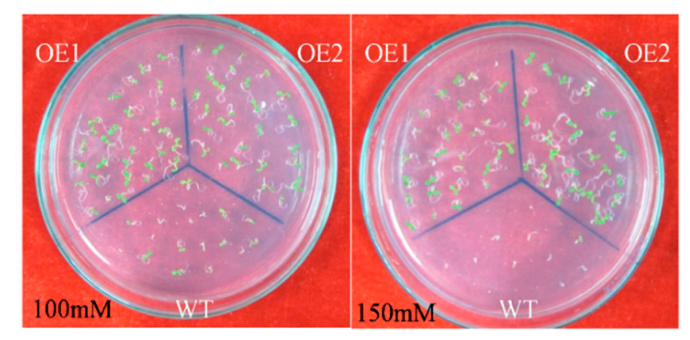

\section{B}

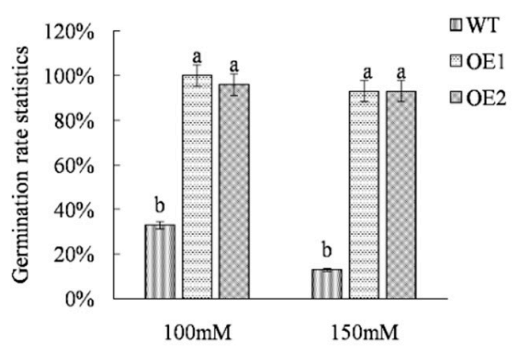

Figure 1. Determination of germination rates of wild-type and transgenic Arabidopsis thaliana under $\mathrm{NaCl}$ stress. (A) Phenotypic observation of wild-type (WT) and transgenic lines under different $\mathrm{NaCl}$ stress. (B) Statistics of germination rate of WT and transgenic ThTr $x 5$ Arabidopsis seeds under $\mathrm{NaCl}$ stress. Three biological replicates were analyzed. Error bars show the average \pm standard deviation of wild-type and transgenic lines (OE1, OE2). Different lowercase letters indicate significant differences ( $p \leq 0.05$ from a Student's $t$ test). WT was Columbia-0 wild-type Arabidopsis thaliana; OE1, OE2 was ThTrx5-Overexpressing Transgenic Lines.

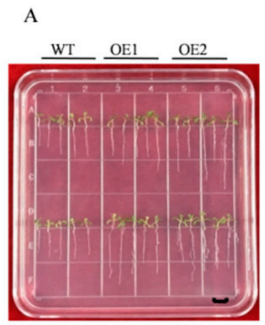

$\mathrm{E}$

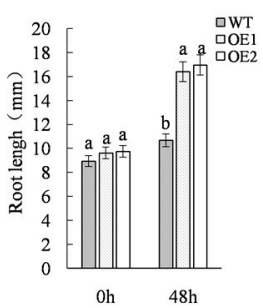

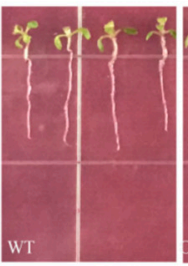

$\mathrm{F}$

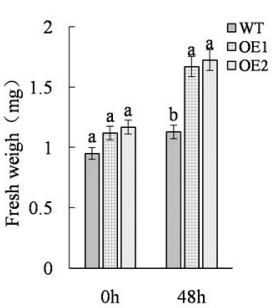

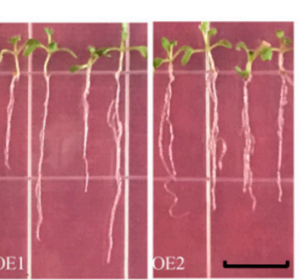

G

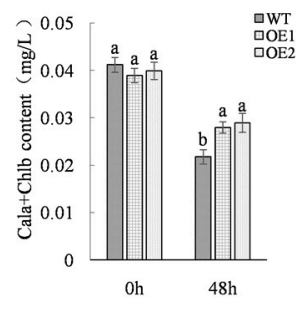

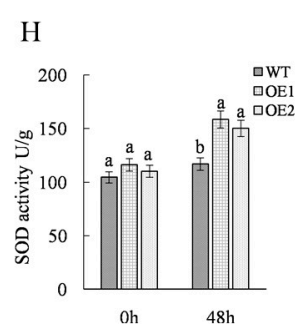

I

$\mathrm{J}$

K
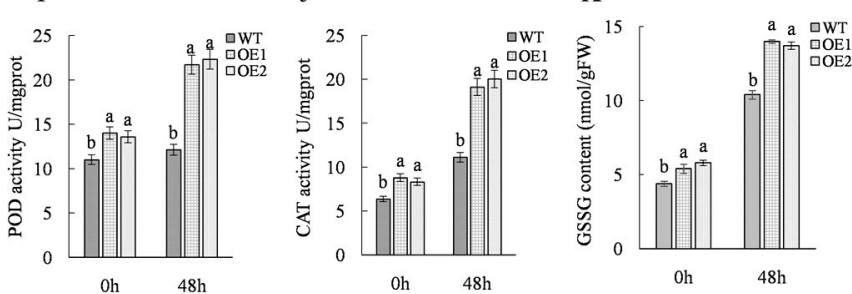

Figure 2. Analysis of Arabidopsis seedlings and determination of physiological indexes treated with $150 \mathrm{mM} \mathrm{NaCl}$. (A) Stress resistance analysis of Arabidopsis thaliana seedlings under $\mathrm{NaCl}$ stress. Bar $5 \mathrm{~mm}$. (B-D) are enlarged views of WT, OE1, and OE2 seedlings grown under $150 \mathrm{mM} \mathrm{NaCl}$, respectively. Bar 
$5 \mathrm{~mm}$. (E) The root length of Arabidopsis seedlings under $\mathrm{NaCl}$ stress. (F) Fresh weight of Arabidopsis seedlings under $\mathrm{NaCl}$ stress. (G) Chlorophyll content in Arabidopsis seedlings under $\mathrm{NaCl}$ stress. (H) SOD (superoxide dismutase) content in Arabidopsis seedlings under $\mathrm{NaCl}$ stress. (I) POD (peroxidase) content in Arabidopsis seedlings under $\mathrm{NaCl}$ stress. (J) CAT (catalase) content in Arabidopsis seedlings under $\mathrm{NaCl}$ stress. (K) GSSG (glutathione) content in Arabidopsis seedlings under $\mathrm{NaCl}$ stress. Three biological replicates were analyzed. Error bars show the average \pm standard deviation of wild-type and transgenic lines (OE1, OE2). Different lowercase letters indicate significant differences ( $p \leq 0.05$ from a Student's $\mathrm{t}$ test).

\subsection{Screening of Interacting Proteins}

\section{Pull Down}

A pull-down technique was used to reveal which proteins ThTrx 5 interacted with during induction of salt tolerance. Using a prokaryotic expression vector, pET41a, ThTrx fusion protein containing the glutathione-S-transferase (GST) Tag, was constructed and expressed in E. coli (DE3), with fusion protein expression confirmed via Western blot analysis using antibody specific for GST (Figure 3A-C). After binding of the fusion protein to a nickel column, the total proteins of wild-type and ThTrx 5 transgenic lines after salt stress were passed through the column and eluted after incubation, respectively. Different bands of WT and transgenic Arabidopsis protein were separated by SDS-PAGE, (Figure 3D,E). Subsequently, differentially expressed proteins were analyzed by mass spectrometry, and resulting data were compared to a protein database (SwissProt 57.15). Five proteins were identified as ThTrx5 interaction partners: CATALASE 3, GLYCERALDEHYDE-3-PHOSPHATE DEHYDROGENASE, PEPTIDYL-PROLYL CIS-TRANS ISOMERASE (CYP20-3), ATP SYNTHASE SUBUNIT BETA, and 2-CYS PEROXIREDOXIN BAS1-LIKE PROTEIN.

A

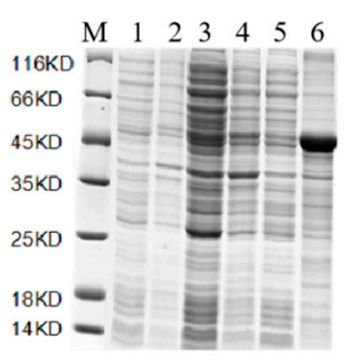

B

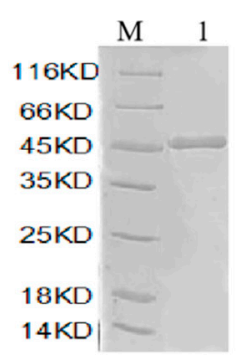

C

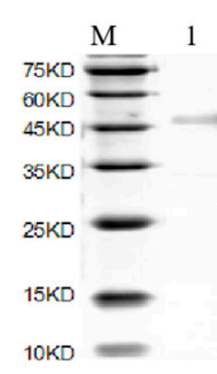

$\mathrm{D}$

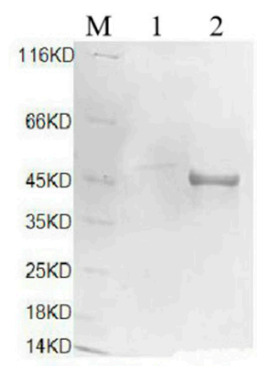

$\mathrm{E}$

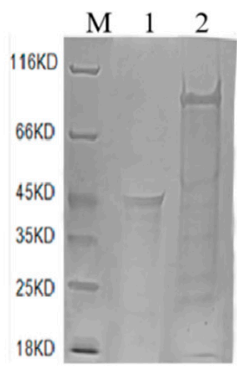

Figure 3. Detection of fusion expressed protein and screening of ThTrx 5 interacting proteins under salt stress. (A) SDS-PAGE analysis of fusion protein. M: protein marker; 1: supernatant before induction; 2: precipitation before induction; 3: supernatant at $20^{\circ} \mathrm{C} ; 4$ : $20^{\circ} \mathrm{C}$ induced precipitation; $5: 37^{\circ} \mathrm{C}$ induced supernatant; 6: $37^{\circ} \mathrm{C}$ induced precipitation; (B) SDS-PAGE analysis of fusion protein purification. M protein marker; 1: Purified protein; (C) Western Blot analysis of fusion protein. M: protein marker; 1: Trx5-GST protein; (D) Identification interaction proteins in WT by SDS-PAGE. M: protein marker; 1: column; 2: total protein of wild-type Arabidopsis after salt treatment; (E) Identification interaction proteins in transgenic Arabidopsis by SDS-PAGE. M: protein marker; 1: Column; 2: Total protein of transgenic ThTrx5 Arabidopsis after salt treatment. GST: glutathione-S-transferase.

\subsection{Transcriptome Analysis}

\subsubsection{Changes in ThTrx5 Gene Expression in Tamarix Hispida under $\mathrm{NaCl}$ Stress}

To determine when ThTr $x 5$ gene responded most significantly under salt stress, we studied by qRT-PCR ThTr $x 5$ and $\alpha$-Tubulin transcript levels in T. hispida at $0,3,6,12,24$, and $48 \mathrm{~h}$ of salt treatment. During exposure of plants to $150 \mathrm{mM} \mathrm{NaCl}$ treatment, ThTr $x 5$ gene expression trends were observed for T. hispida (Figure 4). The expression level of the ThTr $x 5$ gene reached its highest value at $3 \mathrm{~h}$; with 
the prolongation of $\mathrm{NaCl}$ treatment time, the ThTr $x 5$ expression level decreased to its lowest at $12 \mathrm{~h}$ and $24 \mathrm{~h}(<2$-fold $)$ and then increased, and then the expression quantity increased to nearly two times than the value of $24 \mathrm{~h}$ at $48 \mathrm{~h}$.

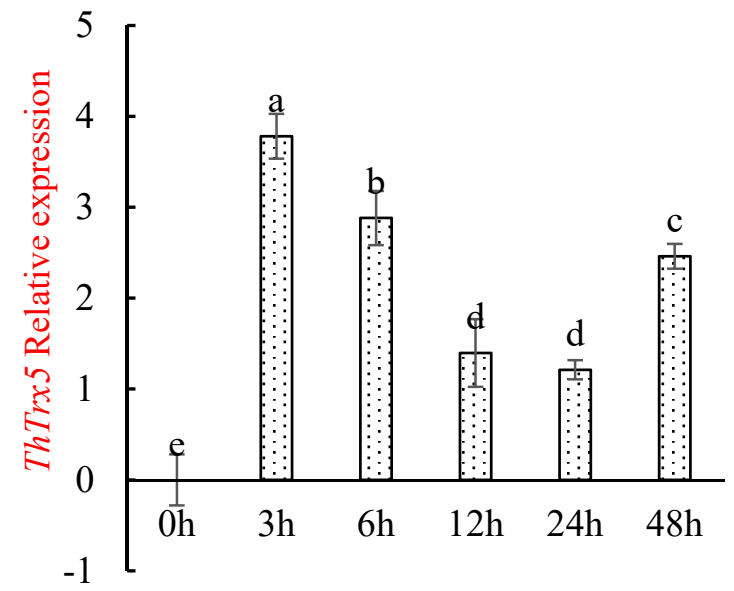

Figure 4. Relative expression of $\operatorname{ThTr} x 5$ gene in T. hispida under $\mathrm{NaCl}$ stress. Error bars show the standard deviation of T. hispida. Different lowercase letters indicate significant differences $(p \leq 0.05$ from a Student's $t$ test).

Studies have shown that homologous genes have similar expression patterns in different species [14]. Therefore, we selected $3 \mathrm{~h}$ of $\mathrm{NaCl}$ exposure as the time point for subsequent transcriptome sequencing and pull-down analysis in Arabidopsis.

\subsubsection{Illumina Sequencing}

To analyze regulatory mechanisms employed by $\operatorname{ThTr} x 5$ during exposure to salt stress, four cDNA libraries were constructed after plants were grown for 7 days post-germination. Two libraries were made from control nontransgenic plants grown under nonstress conditions for $0 \mathrm{~h}$ (designated WT-0h) and plants exposed to $150 \mathrm{mM} \mathrm{NaCl}$ for $3 \mathrm{~h}$ (designated WT-3h). Two additional libraries were constructed as described above from transgenic plants not exposed to stress (designated OE-0h) and plants exposed to $150 \mathrm{mM} \mathrm{NaCl}$ for $3 \mathrm{~h}$ (designated OE-3h). Libraries were sequenced using the Illumina deep-sequencing platform. A total of 7,639,214,7,499,090,7,165,453, and 7,318,039 raw reads were generated by Illumina sequencing. After adapter sequence and low-quality sequences were removed, a final total of 7,478,939, 7,298,276,7,071,661, and 7,309,844 clean reads remained, representing $97 \%$ of sequence obtained before sequence cleanup (Table 1 ).

Table 1. Quality of RNA-Seq of ThTrx5 transgenic lines.

\begin{tabular}{ccccc}
\hline Sample ID & WT-0h & WT-3h & OE-0h & OE-3h \\
\hline Total Reads & $7,639,214(100.00 \%)$ & $7,499,090(100.00 \%)$ & $7,165,453(100.00 \%)$ & $7,318,039(100.00 \%)$ \\
Total BasePairs & $366,468,011(100.00 \%)$ & $357,615,524(100.00 \%)$ & $346,511,389(100.00 \%)$ & $358,182,356(100.00 \%)$ \\
Total Mapped & $4,547,338(60.80 \%)$ & $5,339,751(73.16 \%)$ & $4,739,829(67.03 \%)$ & $5,396,632(73.83 \%)$ \\
Reads & $4,063,215(54.33 \%)$ & $4,756,366(65.17 \%)$ & $4,241,363(59.98 \%)$ & $4,835,471(66.15 \%)$ \\
Perfect Match & $484,123(6.47 \%)$ & $583,385(7.99 \%)$ & $498,466(7.05 \%)$ & $561,161(7.68 \%)$ \\
$<=$ bbp Mismatch & $4,291,451(57.38 \%)$ & $5,119,890(70.15 \%)$ & $4,490,200(63.50 \%)$ & $5,162,943(70.63 \%)$ \\
Unique Match & $255,887(3.42 \%)$ & $219,861(3.01 \%)$ & $249,629(3.53 \%)$ & $233,689(3.20 \%)$ \\
Multi-position & Match & & & \\
Total Unmapped & $2,931,601(39.20 \%)$ & $1,958,525(26.84 \%)$ & $2,331,832(32.97 \%)$ & $1,913,212(26.17 \%)$ \\
Reads & $7,478,939$ & $7,298,276$ & $7,071,661$ & $7,309,844$ \\
Clean Reads & & &
\end{tabular}




\subsubsection{Screening and Analysis of Differentially Expressed Genes}

At $0 \mathrm{~h}$ of $\mathrm{NaCl}$ stress exposure, 500 differential genes were detected in transgenic lines compared with the WT line, of which 115 genes were upregulated and 385 genes were downregulated. At $3 \mathrm{~h}$ of $\mathrm{NaCl}$ stress exposure, the number of differentially expressed genes in transgenic lines versus the WT line was 194, of which 66 genes were upregulated and 128 genes were downregulated. A total of 458 DEGs were specifically expressed in transgenic lines at $0 \mathrm{~h}$ of stress exposure, while 152 DEGs were specifically present in transgenic lines after $3 \mathrm{~h}$ of exposure (Figure 5).

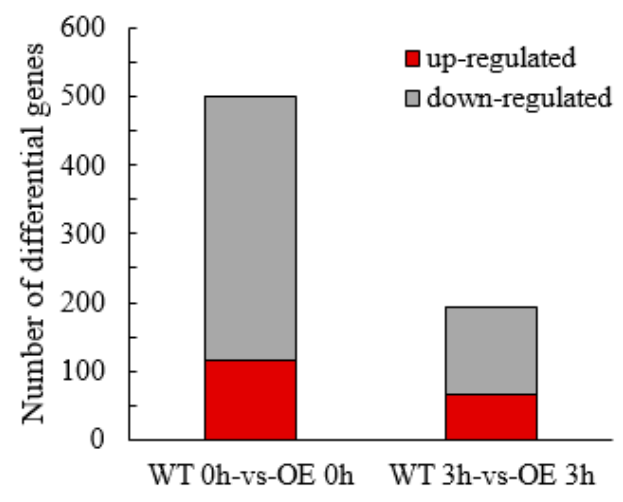

Figure 5. Differential gene distribution map.

\subsubsection{Analysis of GO (Gene Ontology) Enrichment of DEGs}

Functional category enrichment analysis of DEGs between nontransgenic and transgenic lines exposed to $\mathrm{NaCl}$ stress was conducted based on the Gene Ontology (GO) database ( $p$-value $<0.05$, fold-change $>2$ ). Significant GO terms were determined based on a cut-off value of $p<0.05$. GO functional classification of differential genes in the WT $0 \mathrm{~h}$ vs. OE $0 \mathrm{~h}$ transcriptome revealed that DEGs annotation assignments fell into three categories: biological process, cellular component, and molecular function. For the biological process category, DEGs of transgenic lines were enriched for more genes belonging to subprocesses of metabolic process, cellular process, and single-organism process than were enriched in WT lines. In the category of molecular function, differential genes were mainly concentrated in catalytic activity and binding classes. In the category of cellular component, differential genes were mainly concentrated in cell, cell part, and organelle classes. GO analysis revealed differential expression of genes related to binding and catalytic activity in the transgenic lines, including PEROXIDASE9 (AT1G44970.1), CALMODULIN-LIKE 41 (AT3G50770.1), Catalase 3 (AT1G20620.1), CATION EXCHANGER 3 (AT3G51860.1), and FE SUPEROXIDE DISMUTASE 1 (AT4G25100.2), with expression levels of these genes significantly upregulated, respectively, over corresponding wild-type levels. Enrichment of DEGs involved in these processes is likely linked to the transfer of the ThTrx 5 gene into Arabidopsis. Meanwhile, GO analysis of differential genes in WT $3 \mathrm{~h}$ vs. OE $3 \mathrm{~h}$ was also performed. The results showed that enriched DEGs fell within three major categories and were significantly enriched in biological process classes including metabolic process, cellular process, single-organism process, and response to stimulus. For the cellular component category, DEGs were mostly enriched in cell, cell part, and organelle classes. For the molecular function category, DEGs were mostly enriched in binding and catalytic activity classes. GO analysis revealed that DEGs related to binding and response to stimulus pathways were enriched in transgenic lines after salt stress and included PEROXIDASE 52 (AT5G05340.1), JASMONATE-REGULATED GENE 21(AT3G55970.1), DARK INDUCIBLE 11 (AT3G49620.1), and BRUTUS (AT3G18290), which were significantly downregulated by 4 -fold, 8 -fold, 16-fold, and 4-fold, respectively, relative to WT expression levels, while the mRNA expression level of GLUTATHIONE S-TRANSFERASE F2 was significantly upregulated by 8 -fold. Therefore, DEGs for these processes may play an important role in salt tolerance of transgenic Arabidopsis (Figure 6). 


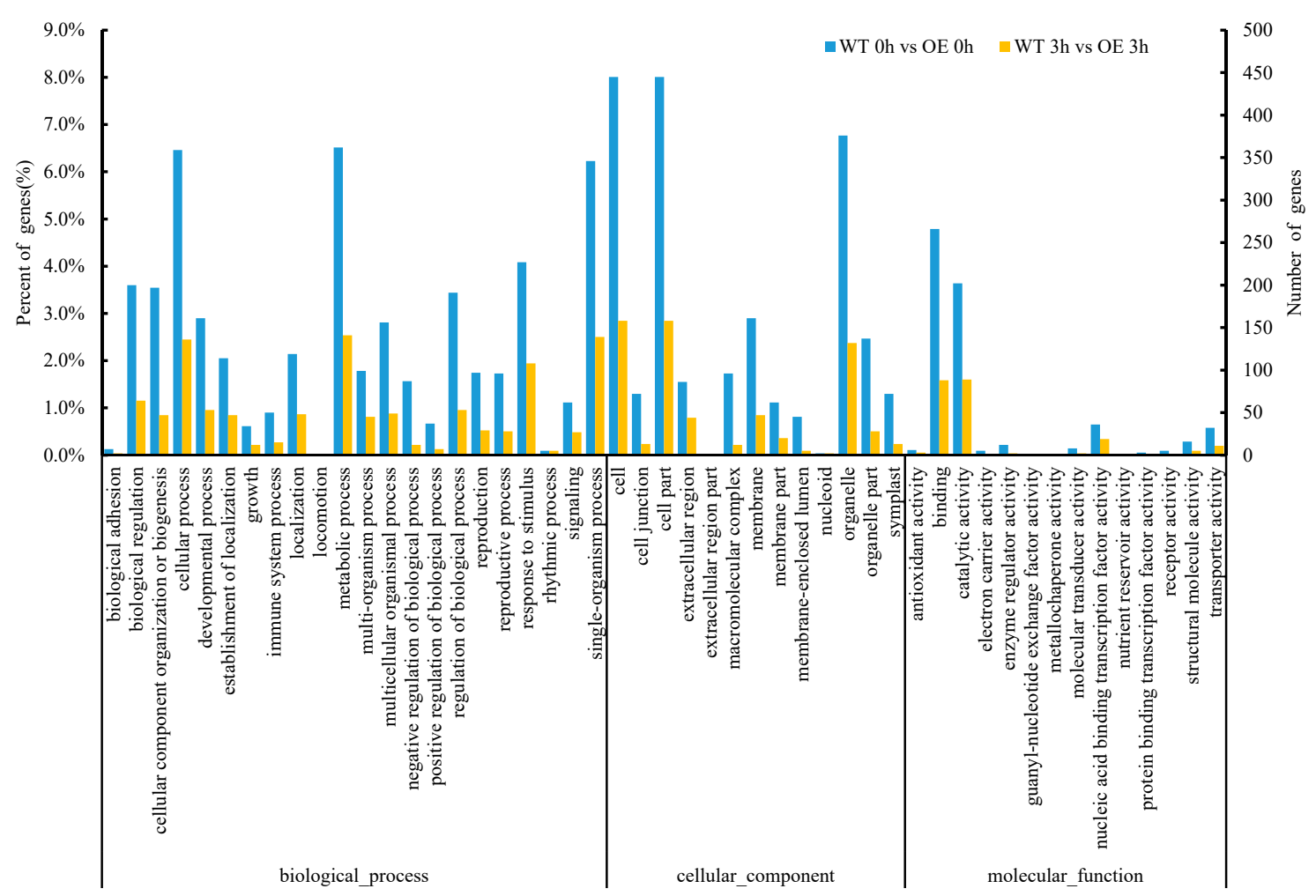

Figure 6. Gene Ontology (GO) classification of WT and ThTrx5 transgenic lines under salt treatment for $0 \mathrm{~h}$ and $3 \mathrm{~h}$.

2.3.5. Analysis of Transcription Factor (TF) Families Represented by DEGs Identified during Salt Stress Exposure

After all unigenes obtained here were compared with the Plant Transcription Factor Database (Plant TFDB), the three TF families with highest numbers of unigene matches included NAC, bHLH, and ORG TF families. Expression patterns of 14 TFs within 10 TF families were significantly different between transgenic and WT lines at $0 \mathrm{~h}$, of which transcriptional expression of 4 TFs were upregulated, including NAC DOMAIN CONTAINING PROTEIN 1 (AT1G56010.2), NAC DOMAIN CONTAINING PROTEIN 102 (AT5G63790.1), WRKY DNA-BINDING PROTEIN 70 (AT3G56400), and YELLOW STRIPE LIKE 1 (AT4G24120.1); meanwhile, transcription levels of 10 TFs were downregulated, such as AP2/B3-LIKE TRANSCRIPTIONAL FACTOR FAMILY PROTEIN (AT1G01030), MYB DOMAIN PROTEIN 48 (AT3G46130.1), NAC DOMAIN CONTAINING PROTEIN 19 (AT1G52890.1), SENESCENCE-ASSOCIATED GENE 21 (AT4G02380.1), and others. At $3 \mathrm{~h}$ of stress exposure, expression of $14 \mathrm{TFs}$ within $10 \mathrm{TF}$ families exhibited significant differences between transgenic versus nontransgenic lines, with 6 upregulated TFs identified that included AP2 (AT4G34400.1), MYB48 (AT3G46130.1), NAC1 (AT1G56010.2), SAG21 (AT4G02380.1), and others, while expression levels of 8 TFs were downregulated, such as NAC domain containing protein 19 (AT1G52890.1), NAC102 (AT5G63790.1), BASIC HELIX-LOOP-HELIX TRANSCRIPTION FACTOR FAMILY PROTEIN101 (AT5G04150.1), OBP3-RESPONSIVE GENE 3 (AT3G56980.1), among others (Figure 7). During salt stress exposure, upregulation of $A P 2$ expression was highest and was 3-fold higher than at $0 \mathrm{~h}$, while downregulation of expression of OBP3-RESPONSIVE GENE 2 (AT3G56970) and ORG3 (AT3G56980.1) were most marked, with transcriptional expression levels exhibiting 2-fold and 3-fold reductions when compared with levels at $0 \mathrm{~h}$, respectively. 


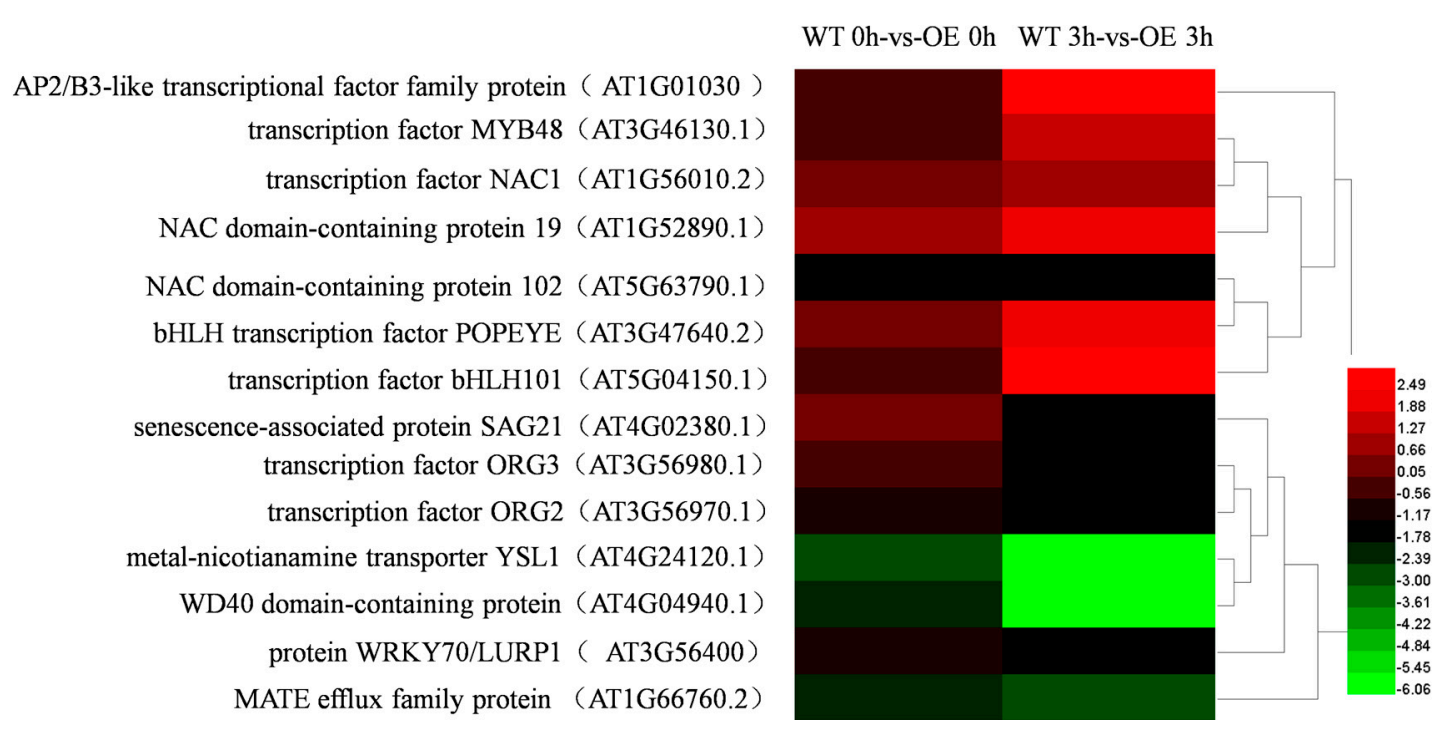

Figure 7. Expression analysis of differentially expressed Transcription Factors (TFs) during stress exposure.

2.3.6. Analysis of DEGs Involved in Hormone Synthesis and Signal Transduction Pathways Triggered by Salt Stress Exposure

Analysis of DEGs involved in hormone signaling pathways during salt stress exposure revealed 13 genes associated with signal transduction pathways involving six hormones, namely ethylene (ETH), jasmonic acid (JA), 6-benzylaminopurine (6-BA), salicylic acid (SA), abscisic acid (ABA), and brassinosteroid (BR); these DEGs exhibited significant expression differences, with the greatest number of DEGs associated with ETH and JA pathways. At 0 h, ERF DOMAIN 53 (AT2G20880.1), GALACTURONOSYLTRANSFERASE-LIKE 2 (AT3G50760.1), SQUALENE SYNTHASE 2 (AT4G34650.1), and GLYCINE-RICH PROTEIN 5 (AT3G20470.1) were upregulated in transgenic ThTr $x 5$ versus WT lines, while nine downregulated genes included ETHYLENE RESPONSE FACTOR-2 (AT5G47220.1), ABI FIVE BINDING PROTEIN 1 (AT1G69260.1), JASMONATE-REGULATED GENE 21 (AT3G55970.1), VEGETATIVE STORAGE PROTEIN 1 (AT5G24780.1), and EXTENSIN 3 (AT1G21310.1). At $3 \mathrm{~h}$, three genes, including ERF2 (AT5G47220.1), EXT3 (AT1G21310.1), GLYCINE-RICH PROTEIN 5 (AT3G20470.1), were induced in transgenic ThTr $x 5$ lines compared with the WT line, with 12 downregulated genes observed that included ERF53 (AT2G20880.1), AFP1 (AT1G69260.1), JRG21 (AT3G55970.1), VSP1 (AT5G24780.1), VEGETATIVE STORAGE PROTEIN 2 (AT5G24770.1), and others (Table 2). Comparison of DEGs related to hormone signaling at $0 \mathrm{~h}$ and $3 \mathrm{~h}$ of stress exposure indicated that upregulated expression level of ERF2 was highest and was 3 -fold greater at $3 \mathrm{~h}$ than at $0 \mathrm{~h}$, while downregulation of expression of JRG21 within the JA signaling pathway was most pronounced at $3 \mathrm{~h}$, with 5 -fold reduction in expression relative to expression at $0 \mathrm{~h}$.

Table 2. Expression analysis of DEGs involved in hormone synthesis and signal transduction pathways during salt stress exposure.

\begin{tabular}{ccccc}
\hline Hormone & Gene & $\begin{array}{c}\mathbf{L o g}_{2} \\
\text { (WT 0 h/Trx 0 h) }\end{array}$ & $\begin{array}{c}\mathbf{L o g}_{2} \\
\text { (WT 3 h/Trx 3 h) }\end{array}$ & Gene Annotation \\
\hline ABA & AT1G52040.1 & -1.466825674 & -1.650566816 & myrosinase-binding protein 1 \\
BR & AT4G34650.1 & 0.06962026 & -1.262992532 & ethylene synthase 2 \\
ETH & AT5G47220.1 & -0.468665009 & 1.963721496 & $\begin{array}{c}\text { factor 2 } \\
\text { fanscription }\end{array}$ \\
& AT2G20880.1 & 0.519653186 & -1.327806826 & ethylene-responsive transcription \\
& AT1G69260.1 & -0.387237409 & -1.327806826 & ABI five binding protein \\
\hline
\end{tabular}


Table 2. Cont.

\begin{tabular}{|c|c|c|c|c|}
\hline Hormone & Gene & $\begin{array}{c}\log _{2} \\
\text { (WT } 0 \mathrm{~h} / \operatorname{Trx} 0 \mathrm{~h} \text { ) }\end{array}$ & $\begin{array}{c}\log _{2} \\
\text { (WT } 3 \mathrm{~h} / \operatorname{Trx} 3 \mathrm{~h} \text { ) }\end{array}$ & Gene Annotation \\
\hline \multirow[t]{5}{*}{ JA } & AT3G55970.1 & -0.457626737 & -2.592176442 & \multirow{5}{*}{$\begin{array}{c}\text { jasmonate-regulated protein JRG21 } \\
\text { Probable } \\
\text { galacturonosyltransferase-like } 2 \\
\text { acid phosphatase VSP1 } \\
\text { acid phosphatase VSP2 } \\
\text { L-ornithine N5-acetyltransferase } \\
\text { NATA1 }\end{array}$} \\
\hline & AT3G50760.1 & 0.502974445 & -1.129387909 & \\
\hline & AT5G24780.1 & -2.57480625 & -2.023514997 & \\
\hline & AT5G24770.1 & -0.608451639 & -1.443297712 & \\
\hline & AT2G39030.1 & -3.23523431 & -2.243926852 & \\
\hline 6-BA & AT1G21310.1 & -0.4968619 & 1.346863463 & response to cytokinin stimulus \\
\hline SA & AT3G20470.1 & 0.527147723 & 1.015449778 & glycine-rich protein 5 \\
\hline
\end{tabular}

2.3.7. Analysis of DEGs Involved in Redox-Based Reaction Processes upon Salt Stress Exposure

A total of 24 DEGs were involved in redox-associated processes. Compared with the WT line, 11 genes were upregulated at $0 \mathrm{~h}$ in transgenic lines, such as FE SUPEROXIDE DISMUTASE 1 (AT4G25100.2), PRX9 (AT1G44970.1), ARABIDOPSIS THALIANA FERRETIN 1 (AT5G01600.1), and FERRITIN 4 (AT2G40300.1), among others, while 9 genes were downregulated, such as CYTOCHROME P450 (AT3G28740.1), BETA-CAROTENE HYDROXYLASE 2 (AT5G52570.1), DARK INDUCIBLE 11 (AT3G49620.1), and others. After $3 \mathrm{~h}$ of stress exposure, 8 genes were upregulated in transgenic versus nontransgenic lines, including FSD1 (AT4G25100.2), PRX9 (AT1G44970.1), and others, while 16 genes were downregulated, including POLYPEPTIDE 13 PUTATIVE CYTOCHROME P450 (AT2G30770.1), Peroxidase 52 (AT5G05340.1), and others (Figure 8). Notably, at $3 \mathrm{~h}$, transcription of the gene encoding ZINC-BINDING DEHYDROGENASE FAMILY PROTEIN (AT5G37940.1) was upregulated by as much as 7-fold relative to its expression at $0 \mathrm{~h}$, while ELI3-2 (AT4G37990.1) was downregulated by 2-fold.

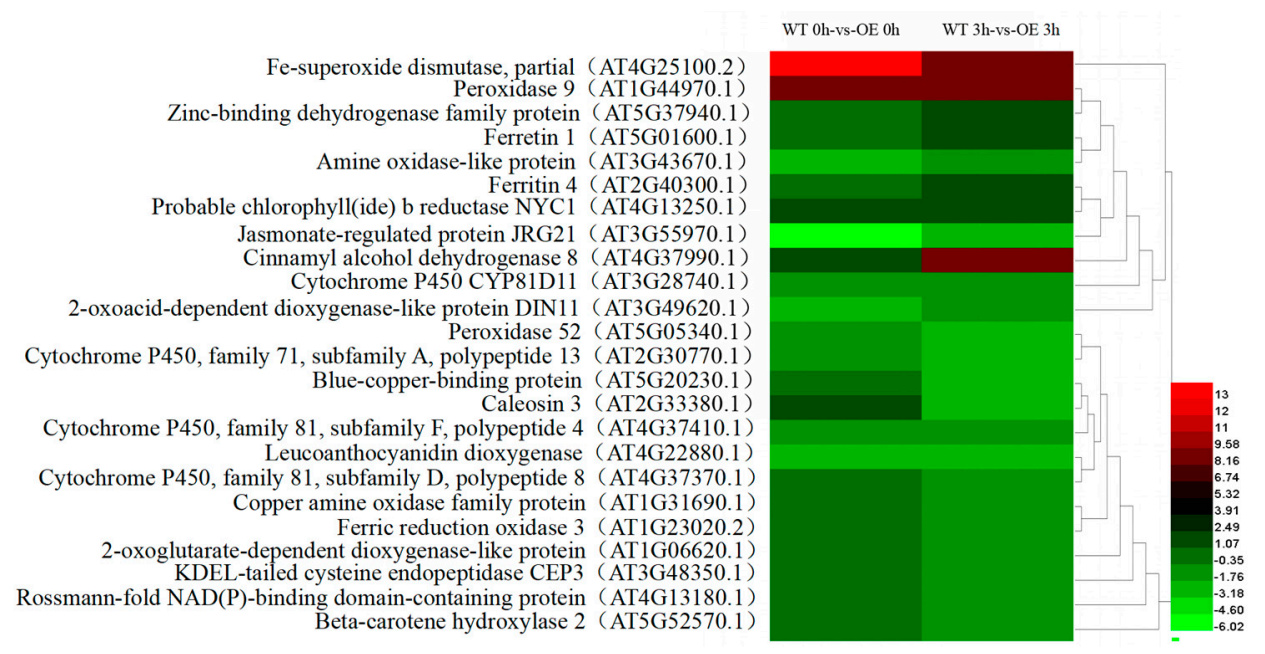

Figure 8. Expression analysis of DEGs involved in redox reaction processes during salt stress exposure.

\subsection{8. qRT-PCR Analysis}

We randomly selected six genes and verified their expression levels under $\mathrm{NaCl}$ stress at $0 \mathrm{~h}$ and $3 \mathrm{~h}$ (Figure 9). The qRT-PCR and transcriptome data trends of FSD1 (AT4G25100.2) and ELICITOR-ACTIVATED GENE 3 (AT4G37990.1) exhibited the same trends (Figure 9A,D), with their expression levels decreasing after $3 \mathrm{~h}$ of $\mathrm{NaCl}$ stress. Meanwhile, AP2 (AT4G34400.1), PRX9 (AT1G44970.1), SERINE CARBOXYPEPTIDASE S28 (AT4G36190.1), and CYTOCHROME P450 (AT4G37410) exhibited a shared upward expression trend (Figure 9B,C,E,F) and attained highest expression levels under $\mathrm{NaCl}$ stress at $3 \mathrm{~h}$. These results demonstrate the reliability of the RNA-seq results. 


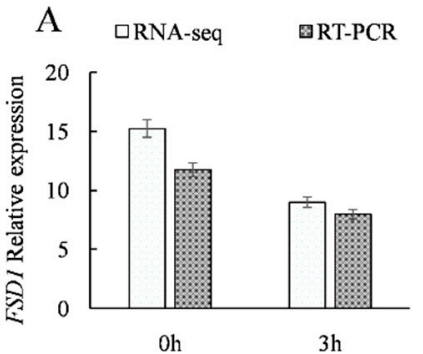

$\mathrm{D}$

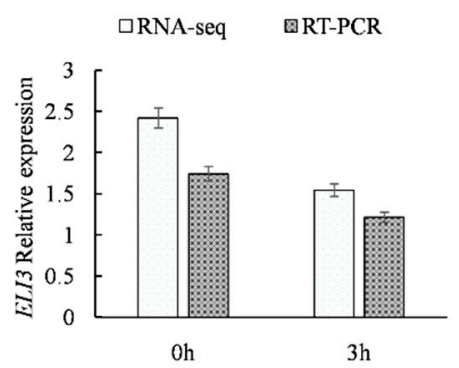

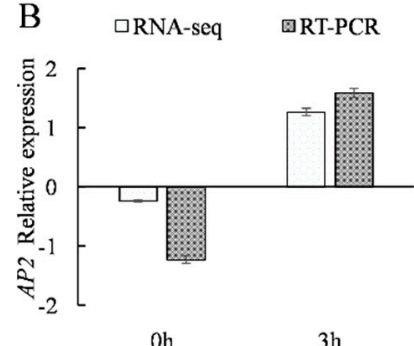

$\mathrm{E}$

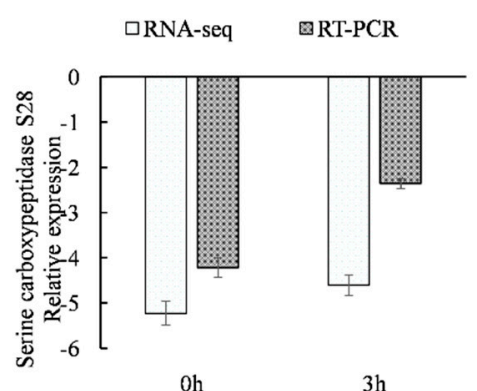

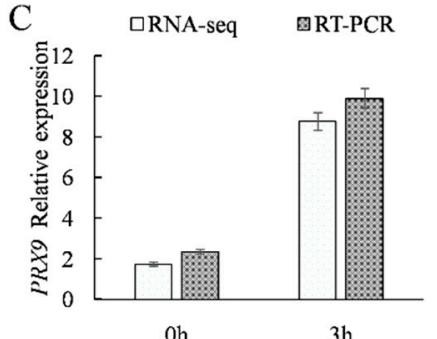

F

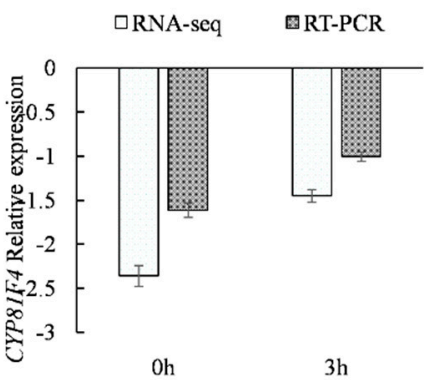

Figure 9. The expression levels of the genes were studied at $0 \mathrm{~h}$ and $3 \mathrm{~h}$ of exposure to $150 \mathrm{mM}$ NaCl. (A) AT4G25100.2; (B) AT4G34400.1; (C) AT1G44970.1; (D) AT4G37990.1; (E) AT4G36190.1; (F) AT4G37410.

\section{Discussion}

\subsection{Overexpressing ThTRX5 Improves Salt Resistance of Arabidopsis Plants}

Thioredoxin, which plays an important role in resistance to drought, oxidation, and heat stresses, has important roles in signal transduction and plant development. In this study, we constructed the plant expression vector pGWB5-ThTrx5 and successfully transformed it into Arabidopsis.

Under $\mathrm{NaCl}$ treatment, seed germination rates of transgenic Arabidopsis lines were significantly greater than the corresponding WT rate (Figure 1). After exposure to $150 \mathrm{mM} \mathrm{NaCl}$ for $48 \mathrm{~h}$, leaves of the WT line yellowed, while most transgenic lines grew normally and exhibited root lengths and fresh weight values that were consistently higher than corresponding values for the WT line (Figure 2). These results suggest that salt tolerance of transgenic lines exceeded that of the nontransgenic line, with results for chlorophyll content and physiological indicators further supporting this conclusion. These results are noteworthy, as the ThTrx5-overexpressing transgenic lines generated here appear to have heightened resistance to salt stress that may be due to the importance of the Trx system and the glutathione-glutaredoxin (Grx) system, which together form the main antioxidant system in plants [15]. The Trx system not only has the same reducibility as the Grx system, but also reduces intracellular oxidized glutathione to maintain the intracellular reduced glutathione concentration [16]. Maintaining high reducing capacity under stress is necessary for plants to cope with adverse conditions and redox level increases [17]. Here, abundances of major antioxidant enzymes and a nonenzymatic antioxidant in plant cells (SOD, POD, CAT, and glutathione, respectively) were further examined in WT and transgenic lines. Under salt stress, levels of SOD, CAT, POD, and GSSG contents in transgenic line plants were higher than levels in WT plants (Figure 2), indicating that ThTr $x 5$ overexpression increased salt tolerance of $A$. thaliana. This result aligns with previously reported results demonstrating that transgenic Arabidopsis overexpressing GhSnRK2 showed obvious salt tolerance that was associated with stress response processes that reduced water loss, regulated cell turgor, maintained relative water content, and controlled proline accumulation [18]. In fact, the importance of glutathione to plant salt stress responses has also been demonstrated in tomato, as glutathione content increased significantly under high salt exposure [19]. 


\subsection{Arabidopsis Proteins Interacting with ThTRX5 Participate with Stress Resistance}

To further investigate salt tolerance mechanisms associated with expression of $\operatorname{ThTr} x 5$, we used pull-down technology to identify five proteins that interact with ThTrx5: catalase 3 (CAT3), glyceraldehyde-3-phosphate dehydrogenase (GAPDH), peptidyl-prolyl cis-trans isomerase (CYP20-3), ATP synthase subunit beta, and a peroxidase, 2-Cys peroxiredoxin BAS1-like protein (Figure 3). We analyzed the domains of three Tamarix and four Arabidopsis m subclasses genes, the results showed that these seven genes all contained highly conserved WCGPC domains, and ThTr $x 5$ had the highest homology with AtTRX-M4 gene of Arabidopsis (Figure S1). Therefore, we selected the AtTRX-M4 gene and predicted the proteins interacting with it by using @STRING CONSORTIUM 2019 software. The prediction results show that 2-Cys peroxiredoxin BAS1-like protein (At5g06290) can interact with it (Figure S4), and the results of BAS1 and pull-down experiments are consistent, the protein and ThTrx5 were both localized in the chloroplast. Interestingly, in the results of protein prediction, we found that AtTRX-M4 also interacted with AtTRX1, and this reaction was also performed in chloroplasts. Glycerol-3-phosphate dehydrogenase (GAPDH) was screened in the pull-down experiment. We found that under reducing conditions, AtTRX1 can activate in chloroplast the glyceraldehyde-3-phosphate dehydrogenase, so we speculated that in the chloroplast, ThTRX5 may interact with TRX1 to catalyze glyceraldehyde-3-phosphate dehydrogenase, and this reaction was under reducing conditions, it was performed in the next step, and because pull-down was an in vitro experiment, it only screened GAPDH.

Important enzymes in maintaining the chloroplast antioxidant protection are the 2-Cys peroxiredoxins [20,21], which are ubiquitous and evolutionary old enzymes reducing $\mathrm{H}_{2} \mathrm{O}_{2}$ and alkyl hydroperoxides [22,23]. These nuclear-encoded proteins are highly abundant within the chloroplast, where they attach to the thylakoid membrane under stress conditions [24]. Peroxiredoxins (Prxs) function both as redox sensory system within the network and as redox-dependent interactors. The processes directly or indirectly targeted by Prxs include gene expression, post-transcriptional reactions, including translation, post-translational regulation, and switching or tuning of metabolic pathways, and other cell activities. Margarete Baier et al. demonstrated that peroxiredoxins respond to ABA signals [25]. BAS1 is a 2-Cys peroxidase (Prx) in plants, scavenges reactive oxygen species (ROS) in vivo, regulates intracellular signaling, and serves as a chaperone $[21,26]$. BAS1 also participates in plant resistance to stress-induced damage. For example, in Arabidopsis exposed to salt, drought or low-temperature stresses, BAS1 was shown to be important for removal of toxic ROS, as well as for antioxidant defense and redox signaling [27].

Glycerol-3-phosphate dehydrogenase (GAPDH) is a ubiquitous enzyme involved in plant life-sustaining activities, including growth and development, as well as in stress responses to high salt or drought, where the enzyme response is very rapid. Notably, the importance of this enzyme to plant salt tolerance was demonstrated in a study showing that the NP-GAPDH gene in rice exhibited significantly increased expression under drought and high salt conditions [28].

\subsection{ThTrx5 Participates in the Redox Process, TF Expression, and Hormone Signal Transduction}

Tolerance of plants to environmental stress depends on their efficiency in sensing stress signals and in activating stress response mechanisms [29]. Plants perceive external salt stress through signal receptors on cell membranes that, through a series of signal transduction pathways and transcriptional regulation mechanisms, induce changes in gene expression downstream of salt stress receptors to control plant growth and development. Here, DEGs in transgenic and nontransgenic lines were analyzed at $0 \mathrm{~h}$ and $3 \mathrm{~h}$ of $\mathrm{NaCl}$ treatment, resulting in identification of $694 \mathrm{DEGs}$. Some of these DEGs were associated with redox processes, transcriptional regulation, and hormone signal transduction, suggesting that transcriptional regulation may underlie salt tolerance of ThTrx5-overexpressing lines. As clues to transcriptional regulation targets involved in salt tolerance, at $3 \mathrm{~h}$ of $\mathrm{NaCl}$ treatment, expression levels of peroxidase and superoxide dismutase in transgenic lines were upregulated by 500and 20-fold, respectively; after stress exposure, expression of a calmodulin-like gene in transgenic lines was upregulated relative to WT expression (Figure 8). Thus, ThThx5 appears to induce expression of 
superoxide dismutase, peroxidase, and calmodulin-like genes during the Arabidopsis salt stress response. Among them, PRX9 and FSD1 were identified and categorized according to GO classification (Figure 8). Meanwhile, Grx and Trx systems, considered parallel redox systems operating independently of one another, may also play a role in salt tolerance; here, transcriptome data indicated that during salt stress, Grx gene expression was downregulated in transgenic ThTr $x$-overexpressing lines relative to expression in the WT line, reflecting the complementary relationship between Grx and Trx systems.

In conclusion, the triggering of changes in ThTr $x 5$ expression is important for plant adaptation to salt stress. Specifically, ThTrx 5 production is induced during high salt stress exposure via a specific signal-based activation mechanism. ThTrx 5 then triggers regulatory pathways that rapidly and broadly alter downstream gene expression and perpetuate stress signal transmission, ultimately activating several protein kinases or phosphatases that enable plants to quickly respond to salt stress.

The molecular mechanism of salt stress-related gene expression and signal transduction is very complex and is the result of synergy among multiple genes and multiple pathways. Hormones play important regulatory roles in adaptation to environmental stresses [30] and are known to participate in early regulation of the plant salt stress response through complex interaction networks [31]. One such hormone, ABA, has been shown to have an important role in plant drought resistance, with a molecular mechanism of action that is relatively clear. However, in this study, expression changes of ABA-related gene pathways were not obvious (Table 2), indicating that ThTr $x 5$ did not improve plant salt tolerance via a mechanism involving ABA-related signaling pathways. Meanwhile, other studies have reported that ABA, GA, SA, Cytokinins (CK), and Indole-3-acetic acid (IAA) exhibit antagonistic effects, with ABA negatively regulating the SA-dependent defense response pathway [32], while JA and ETH often synergistically regulate plant biological responses to abiotic and biotic stresses [33]. Here, the results of DEGs analysis showed that genes involved in SA, ETH, and JA transduction pathways were most abundant, with transcript levels changing to differing degrees between $0 \mathrm{~h}$ and 3 $\mathrm{h}$ of $\mathrm{NaCl}$ exposure (Table 2). Thus, pathways involving ETH, JA, and SA may be responsible for salt resistance of ThTrx5-overexpressing transgenic lines.

Environmental stress can affect various normal physiological and metabolic processes in plants. Stress signals sensed by receptors on cell surfaces trigger associated signal transduction pathways, through which TFs regulate plant growth and development and adaptation to stress $[34,35]$. When gene expression levels of ThTrx5-overexpressing and WT lines under salt stress were analyzed, it was found that transcript levels encoding transcription factor families (such as MYB, WD40, YSL, ORG, WRKY, AP2, NAC, BHLH, etc.) were significantly induced (Figure 7). These results align with results of a previous study showing that under abiotic stress, NAM ATAF1/2/CUC2 (NAC) family gene expression increased and induced expression of other stress-related genes; in addition, overexpression of NAC TF genes significantly improved plant stress resistance [36]. As another example, under high salt, drought, and low-temperature stress, expression of the $M s N A C 1$ in alfalfa was upregulated then downregulated [37]. In this study, three NAC family genes exhibited different transcriptional expression levels, whereby NAC1 was upregulated while NAC19 and NAC102 were downregulated (Figure 7). Another TF family, the basic/helix-loop-helix (BHLH) family, has been shown to play an important role in JA-mediated responses within abiotic stress regulatory networks [38]. Meanwhile, APETALA2/ethylene-responsive factor (AP2) family TFs also have been reported to be associated with abiotic stress resistance [39], with some members of this TF family shown to be pivotal members of JA and ETH signaling pathways that have important regulatory roles in abiotic stress adaptation [33]. Indeed, JA and ETH pathways were observed in this work to synergistically enhance salt tolerance of ThTr $x 5$ transgenic lines, supporting AP2 family gene involvement in salt tolerance in our model system. Finally, as yet another TF family, the WRKY family, exhibited upregulated expression in transgenic lines after salt stress (Figure 7), we speculate that WRKY TFs play regulatory roles in salt tolerance of transgenic ThTrx5-overexpressing lines. In fact, this result aligns with results of a previous study showing that overexpression of WRKY genes GmWRKY13, GmWRKY21 and GmWRKY54 in Arabidopsis led to improved stress resistance [40]. 


\subsection{ThTrx5 Regulates Biological and Metabolic Pathways via Protein Interactions}

Although accumulation of $\mathrm{H}_{2} \mathrm{O}_{2}$ during plant salt stress exposure results in cell damage, ThTr $x 5$-overexpressing lines exhibited lower oxidative damage than did WT plants, a result likely attributable to CAT3 activation triggered by transmembrane flow of calcium ions and release of cytoplasmic calcium stores. It is also possible that BAS1, shown here to directly bind to ThTrx5, may participate in redox reactions and regulate the binding of $\mathrm{CaCl}_{2}$ to calmodulin, while also catalyzing $\mathrm{O}_{2}$ production, leading to a reaction between $\mathrm{O}_{2}$ and benzoic acid to form SA to trigger the plant defense response. Meanwhile, environmental stress may also stimulate ROS production and increase antioxidant enzyme activities that subsequently increase levels or activation of downstream signaling factors, such as cytosolic calcium ions and plasma membrane NADPH oxidase, to explain the high degree of transcriptome representation of calmodulin, NADPH, and SA signaling pathway genes observed in this study.

\section{Materials and Methods}

\subsection{Materials}

\subsubsection{Plant Materials and Growth Conditions}

Seedlings of Tamarix hispida were grown in pots containing a mixture of turf peat and sand $(2: 1 \mathrm{v} / \mathrm{v})$ in a greenhouse under controlled conditions of 70-75\% relative humidity, a light/dark cycle of $14 / 10 \mathrm{~h}$ (with the light cycle beginning at 7:00 a.m. daily), and a constant temperature of $24{ }^{\circ} \mathrm{C}$. Two-month-old seedlings were used for cloning and expression pattern of the ThTr $x 5$ gene.

Arabidopsis thaliana salt-sensitive strain Columbia-0 (Col-0) was used in subsequent studies. Transgenic and wild-type (WT) Arabidopsis seedlings were grown on 1/2 Murashige and Skoog (MS) agar plates in a climate-controlled chamber under fluorescent light $\left(400 \mu \mathrm{mol} \cdot \mathrm{m}^{-2} \cdot \mathrm{s} ; 16 \mathrm{~h} \mathrm{light} / 8 \mathrm{~h}\right.$ dark $)$ at $22 \pm 2{ }^{\circ} \mathrm{C}$, then after $8-10 \mathrm{~d}$ were transplanted into soil and grown in environmentally controlled growth cabinets as described above.

\subsubsection{Processing Method}

T. hispida seedlings cultivated in the soil for 2 months were selected, and were irrigated with $150 \mathrm{mM} \mathrm{NaCl}$, and then the leaves of 10 samples were harvested at $0,3,6,12,24$, and $48 \mathrm{~h}$ of $\mathrm{NaCl}$ exposure, respectively. Harvested samples were frozen quickly in liquid nitrogen, then stored at $80^{\circ} \mathrm{C}$ for RNA analysis.

Homozygous seeds of transgenic ThTrx 5 and wild-type Arabidopsis were sown on 1/2 MS medium containing $100 \mathrm{mM}$ or $150 \mathrm{mM} \mathrm{NaCl}$ after vernalization, then cultured under light-controlled conditions (16 h light/ $8 \mathrm{~h}$ dark). Germination rate was recorded 7 days later for triplicate groups of samples, with each group containing 30 seeds per line. Transgenic and WT seedlings possessing two cotyledons after 7 days of germination were transferred and cultured in a climate-controlled room in $1 / 2 \mathrm{MS}$ or $1 / 2 \mathrm{MS}$ medium containing $150 \mathrm{mM} \mathrm{NaCl}$ for $48 \mathrm{~h}$, then 30 seedlings were harvested at $0 \mathrm{~h}$ and $48 \mathrm{~h}$ in order to determine fresh weight, root length, and SOD, POD, CAT, and GSSG content values in triplicate using GSH and GSSH detection kits (Biyuntian Company) and SOD, POD, and CAT determination kits (Nanjing Jianjian Bioengineering Research Institute). Chlorophyll content was determined using the method of Marker [41] in triplicate in groups each containing 30 embryos. Plants were placed in medium containing $150 \mathrm{mM} \mathrm{NaCl}$, then 60 samples were harvested at $0 \mathrm{~h}$ and $3 \mathrm{~h}$ of $\mathrm{NaCl}$ exposure. Harvested samples were frozen quickly in liquid nitrogen, then stored at $80^{\circ} \mathrm{C}$ for use in pull-down and transcriptome analysis. 


\subsection{Gene Cloning and Vector Construction}

\subsubsection{ThTrx5 Gene Cloning and Expression Vector Construction}

Total RNA of roots of T. hispida plants was extracted using the CTAB method [42], then subjected to reverse transcription using ReverTra Ace ${ }^{\circledR}$ qPCR RT Master Mix with gDNA Remover (Toyobo Biotechnology Co., Ltd., Shanghai, China). Based on the ORF sequence within the ThTrx 5 gene, primers were designed (upstream primer, 5' -AATCTATGATTGCTCCTTC C-3'; downstream primer, 5'-GCCAGCTCATTAACAACC-3'). Each PCR reaction contained $2.5 \mu \mathrm{L}$ KOD Plus Buffer Solution, $2.5 \mu \mathrm{L} \mathrm{dNTPs}(2.0 \mathrm{mmol} / \mathrm{L}), 0.5 \mu \mathrm{L}$ cDNA, upstream and downstream primers $(10 \mu \mathrm{mol} / \mathrm{L}, 0.75 \mu \mathrm{L}$ each), $1 \mu \mathrm{L} \mathrm{MgSO}_{4}$, and $0.5 \mu \mathrm{L} \mathrm{KOD}$, with total reaction volume adjusted to $20 \mu \mathrm{L}$ with ddH ${ }_{2} \mathrm{O}$. Amplification was performed using thermal cycling steps of 1 cycle of $94^{\circ} \mathrm{C}$ for $4 \mathrm{~min}, 35$ cycles of $\left(94{ }^{\circ} \mathrm{C}\right.$ for $45 \mathrm{~s}, 58^{\circ} \mathrm{C}$ for $45 \mathrm{~s}, 68^{\circ} \mathrm{C}$ for $30 \mathrm{~s}$ ), and 1 final extension step of $68^{\circ} \mathrm{C}$ for $10 \mathrm{~min}$. Amplified products were detected via electrophoresis on $0.8 \%$ agarose gels. After PCR product purification, Tri-Octyl Phosphine Oxide (TOPO) cloning of PCR products was carried out, followed by transformation of recombinant plasmid into Escherichia coli Trans $5 \alpha$ cells using a heat shock-based method. After confirmation of the construct using DNA sequencing, the insert of the TOPO recombinant plasmid was site-specifically recombined with pGWB5 vector via an LR reaction, then the completed reaction solution was transformed into E. coli Trans $5 \alpha$. Positive clones were detected via PCR (using specific primers), followed by $0.8 \%$ agarose gel electrophoresis to screen for inserts of predicted size. ThTr $x 5$ is in the pGWB5 vector and is driven by the $35 \mathrm{~S}$ promoter.

\subsubsection{Construction of Fusion Protein Expression Vector}

Using recombinant plasmid pENTR-Trx5 as template, the target fragment was amplified using PCR using amplification conditions described above. Upstream and downstream primers were 5'-CACCCCGCGGAATCTATGATTGCTCCTTCC-3' (Sac II); 5'-CTCGAGGCCAGCTCATT AACAACC-3' (Xho I). Target product obtained via PCR amplification was digested with restriction endonucleases Sac II and Xho I, then ligated to Sac II/Xho I-digested expression vector pET-41a, which contains glutathione-S-transferase (GST) Tag. Ligated product was transformed into E. coli Trans $5 \alpha$ competent cells, then cells were plated onto agar medium containing kanamycin (Kan, $50 \mu \mathrm{g} / \mathrm{mL}$ ) and allowed to grow until isolated colonies were visible. DNA extracted from colonies was screened for ThTr $x 5$-containing inserts, then positive colonies for inserts were cultured, and recombinant plasmid DNA extraction performed using the BioFlux Biospin Plasmid DNA Extraction Kit (Fluxion Biosciences, Alameda, CA, USA). Confirmation of recombinant plasmid pET41a-Trx5 assembly was performed using double-digestion with $S a c$ II and Xho I, followed by agarose gel electrophoresis and DNA sequencing. Next, $1 \mu \mathrm{L}$ of recombinant pET-41a plasmid was transformed into Rosetta-gami B(DE3) cells via heat shock, followed by growth in Luria-Bertani (LB) medium containing $30 \mathrm{ug} / \mathrm{mL} \mathrm{Kan} \mathrm{and}$ $34 \mathrm{ug} / \mathrm{mL}$ chloramphenicol (Cm).

\subsection{3. qPT-PCR}

In T. hispida, total RNA from leaves was extracted using the CTAB method, and reverse transcribed after $\mathrm{NaCl}$ treatment for $0,3,6,12,24$, and $48 \mathrm{~h}$. Primers were designed based on the full-length cDNA sequence of the ThTrx 5 gene (Table 3 for primers). The $\alpha$-tubulin gene was used as internal references to normalize the amount of total RNA present in each reaction.

In Arabidopsis thaliana, total RNA of WT and ThTrx5-overexpressing lines was extracted after $\mathrm{NaCl}$ treatment for $0 \mathrm{~h}$ and $3 \mathrm{~h}$, followed by reverse transcription performed on all samples. Concurrently, six genes were randomly selected from transcriptome DEGs, with $\alpha$-Tubulin serving as internal reference gene (Table 3 for primers). Expression levels of surrogate genes in transgenic and WT plants were analyzed to verify the reliability of transcriptome data.

For use as template, cDNA was diluted 10-fold in real-time quantitative PCR reactions containing $6 \mu \mathrm{L}$ Top qMix, $0.24 \mu \mathrm{L}$ Passive Reference Dye, $2 \mu \mathrm{L}$ cDNA, and $0.24 \mu \mathrm{L}$ each of $10 \mu \mathrm{mol} / \mathrm{L}$ upstream 
and downstream primers, then adjusted to a total reaction volume of $12 \mu \mathrm{L}$ with $\mathrm{ddH}_{2} \mathrm{O}$. DNA amplification was conducted using an ABIPRISM $^{\circledR} 7500$ real-time PCR instrument with cycling parameters of predenaturation at $94^{\circ} \mathrm{C}$ for $30 \mathrm{~s}$, followed by 45 cycles of $\left(94{ }^{\circ} \mathrm{C}\right.$ for $5 \mathrm{~s}, 56^{\circ} \mathrm{C}$ for $15 \mathrm{~s}$, $72{ }^{\circ} \mathrm{C}$ for $34 \mathrm{~s}$ ), and a final cycle of $95^{\circ} \mathrm{C}$ for $15 \mathrm{~s}, 60^{\circ} \mathrm{C}$ for $1 \mathrm{~min}$, and $95^{\circ} \mathrm{C}$ for $30 \mathrm{~s}$. All samples were amplified in triplicate, and relative quantitative analysis of genes was performed using the $-\Delta \Delta \mathrm{Ct}$ method. The ordinate is the value taken by $\log _{2}$.

Table 3. PCR primer sequences.

\begin{tabular}{|c|c|c|}
\hline Primer Name & Forward Primer $\left(5^{\prime} \rightarrow 3^{\prime}\right)$ & Reverse Primer $\left(5^{\prime} \rightarrow 3^{\prime}\right)$ \\
\hline$\alpha$-Tubulin & 5'-GCACTGGCCTCCAAGGAT-3' & 5'-TGGGTCGCTCAATGTCAAGG-3' \\
\hline $\operatorname{ThTr} x 5$ & 5'-AATCTATGATTGCTCCTTCC-3' & 5'-GCCAGCTCATTAACAACC-3' \\
\hline AT4G25100.2 & 5'-GATGCTTTGGAGCCGCATATG-3' & 5'-GAAGAACTCGTGGTTCCACG-3' \\
\hline AT4G34400.1 & 5'-CAGCTCAGAGTTCATGGTGATC-3' & 5'-GTGAGCTCCATTATAGGCAAAGG-3' \\
\hline AT1G44970.1 & 5'-CGTGAGTGGATTCCCTAAACAATC-3' & 5'-CACTCCAAACCCAGAGATTGG-3' \\
\hline AT4G37990.1 & 5'-CGAAAGACAATTCCGGAGTTCTC-3' & 5'-CAGTCACCACGCCCACGATC-3' \\
\hline AT4G36190.1 & 5'-GGTTACTGCAACCTCGTAGGATTTC-3' & 5'-GGTGATTCCATTGCAAGGTCC-3' \\
\hline AT4G37410 & 5'-CCTCATCAAACCGCCGGTTC-3' & 5'-AGCAATGTATTTGGAGGTTAGAAAACG-3' \\
\hline
\end{tabular}

\subsubsection{Data Analysis}

The GO analysis method is a hypergeometric test algorithm; the DEG analysis software is based on a Poisson distribution model used with the RPKM algorithm; SPSS 7.0 statistical software was used for data analysis, $p \leq 0.05$ from a Student's $t$ test. All experiments were repeated three times.

\subsection{Preparation of Engineered Bacteria and Arabidopsis Transformation}

The pGWB5-Trx5 plasmid construct was transferred into Agrobacterium tumefaciens EHA105 by electroporation, and cells were grown on Slab LB medium containing $50 \mathrm{mg} / \mathrm{mL}$ Kan and $50 \mathrm{mg} / \mathrm{mL}$ rifampicin (Rif). A single colony was inoculated into $5 \mathrm{~mL}$ of Luria-Bertani (LB) medium containing antibiotics Kan and Rif, then incubated at $28^{\circ} \mathrm{C}$ overnight, then cultured a second time in $50 \mathrm{~mL}$ of fresh LB medium without antibiotics at $28{ }^{\circ} \mathrm{C}$ overnight. A. tumefaciens cells were harvested after centrifugation for $15 \mathrm{~min}$ at $5000 \mathrm{rpm}$, resuspended in 5\% sucrose water solution, adjusted to an $\mathrm{OD}_{600}$ of 0.6, then were used to transform Arabidopsis (Col-0) using a floral dip-based transformation method [43]. Transformants were selected by planting seeds onto $1 / 2 \mathrm{MS}$ medium containing $50 \mathrm{mg} / \mathrm{L}$ Kan. Transgenic lines were confirmed using PCR, then propagated to the $\mathrm{T}_{3}$ generation, then rescreened to confirm successful development of stable transgenic lines (homozygous for the ThTr $x 5$ gene) for use in subsequent experiments.

\subsection{Screening of Interacting Proteins}

\subsubsection{Induction of Protein Expression}

A single colony of Rosetta-gami B(DE3) cells was selected then cultured in vitro in $4 \mathrm{~mL}$ LB medium (containing $30 \mu \mathrm{g} / \mathrm{mL} \mathrm{Kan,} 34 \mu \mathrm{g} / \mathrm{mL} \mathrm{Cm}$ ) at $37^{\circ} \mathrm{C}$ for $12 \mathrm{~h}$ with shaking (220 rpm). Next, the culture was transferred to a culture flask containing $4 \mathrm{~L}$ of LB medium $(30 \mu \mathrm{g} / \mathrm{mL} \mathrm{Kan}, 34 \mu \mathrm{g} / \mathrm{mL}$ $\mathrm{Cm}$ ), for a culture dilution of 1:1000. Induction was performed at $20^{\circ} \mathrm{C}$ and $37^{\circ} \mathrm{C}$, respectively, and finally, $37^{\circ} \mathrm{C}$ was the best induction condition. Therefore, the flask was incubated at $37^{\circ} \mathrm{C}$ with shaking at $200 \mathrm{rpm}$ until the $\mathrm{OD}_{600}$ reached 0.6. Isopropyl- $\beta$-D-thiogalactopyranoside (IPTG) was added to a concentration of $0.2 \mathrm{mmol} / \mathrm{L}$ to induce protein expression, and the flask was incubated at $37^{\circ} \mathrm{C}$ with shaking (200 rpm) for $5 \mathrm{~h}$. E. coli cells were collected, then suspended in buffer ( $50 \mathrm{mM}$ Tris, $300 \mathrm{mM}$ $\mathrm{NaCl}, 0.1 \%$ Triton $\mathrm{X}-100, \mathrm{pH}$ 8.0). Cells were broken using low-temperature ultrasound for $20 \mathrm{~min}$, then centrifuged for $20 \mathrm{~min}$ at $12000 \mathrm{rpm}$ and $4{ }^{\circ} \mathrm{C}$. The supernatant was diluted in equilibrium buffer (50 mM Tris, $100 \mathrm{mM} \mathrm{NaCl}, 0.1 \%$ Tween-20, $1 \mathrm{mM}$ Phenylmethylsulfonyl fluoride (PMSF), $1 \mathrm{mM}$ DL-Dithiothreitol (DTT) to a volume equivalent to the original volume before centrifugation, then 
SDS-PAGE electrophoresis and western blot were performed to analyze ThTrx fusion protein obtained using GST antibody.

\subsubsection{Pull-Down}

The wild-type and ThTrx 5 transgenic Arabidopsis thaliana growing for $7 \mathrm{~d}$ were selected, treated with $150 \mathrm{mmol} / \mathrm{L} \mathrm{NaCl}$ for $3 \mathrm{~h}$, and the leaves were collected. Total protein of transgenic and nontransgenic Arabidopsis lines was extracted using a One-Step Plant Protein Extraction Kit (Shanghai Shenggong Biotechnology Co., Ltd., Shanghai, China). Extracted total protein was concentrated to a volume of $400 \mu \mathrm{L}$ using a centrifugal filter cartridge (Millipore, MA, USA; Agent: Bioflux, Biotech Innovation Technology Co., Ltd., Beijing, China). After Coomassie Brilliant Blue staining to confirm the amount of protein, approximately $50 \mu \mathrm{g}$ of total protein from each transgenic and nontransgenic Arabidopsis line was incubated with nickel agarose resin beads for $4 \mathrm{~h}$ at $4{ }^{\circ} \mathrm{C}$. Beads were then washed 5 times with $1 \mathrm{~mL}$ of elution buffer (50 mM Tris, $100 \mathrm{mM} \mathrm{NaCl}, 0.1 \%$ Tween-20, $1 \mathrm{mM}$ PMSF, $1 \mathrm{mM}$ DTT, $500 \mathrm{mM}$ imidazole). SDS-PAGE was performed. The bands that appeared in transgenic plants and wild type were excised for differential bands for analysis by mass spectrometry.

\subsubsection{Mass Spectrometry}

Mass spectrometry was conducted using an Nd: YAG laser delivering light of wavelength $355 \mathrm{~nm}$ using an acceleration voltage of $2 \mathrm{kV}$, with data collection using positive ion and automatic data acquisition modes. The Peptide mass fingerprinting (PMF) mass scan range was 800-4000 Da. For tandem mass spectrometry (MS/MS) analysis, eight precursor ions were selected for each sample point; secondary MS/MS laser excitation sampling was set to 2500 times, collision energy was set to $2 \mathrm{kV}$, and Collision-Induced Dissociation (CID) was turned off.

\subsection{Transcriptome Analysis}

\subsubsection{RNA Extraction and Differential Expression Library Construction}

Total mRNA was isolated using the CTAB method, then was digested with DNase I (RNase-free) for $30 \mathrm{~min}$ at $37^{\circ} \mathrm{C}$ to remove genomic DNA contaminants. RNA integrity was assessed using a NanoPhotometer ${ }^{\circledR}$ Spectrophotometer (IMPLEN, Westlake Village, CA, USA) and RNA Nano 6000 Assay Kit, and data were analyzed using the Agilent Bioanalyzer 2100 System (Agilent Technologies, Santa Clara, CA, USA). Total mRNA (20 $\mu$ g per sample) with RNA integrity (RIN) score greater than 8.0 was sent to Huada Gene Technology (Shenzhen, China) for construction of individual cDNA libraries for Illumina sequencing. RNA sequencing (RNA-seq) was performed using an Illumina kit and standard cBot System using sequencing protocols provided by the manufacturer. Briefly, mRNA was isolated using oligo (dT) cellulose and broken into short fragments by addition of fragmentation buffer. Using these short fragments as templates, first-strand cDNA and second-strand cDNA were synthesized. Sequencing adapters (used to distinguish among sequences derived from different libraries) were ligated to the short fragments after purifying fragments using a QIAQuick PCR Extraction Kit. Fragments $200 \pm 25$ bp in length were then separated by agarose gel electrophoresis and selected for use as sequencing templates in PCR amplification. All experiments were conducted using three biological replicates per experimental sample. Finally, the two libraries were sequenced using Illumina HiSeq ${ }^{\text {TM }} 2000$.

\subsubsection{De Novo Assembly and Functional Annotation}

To obtain accurate data, raw reads were first filtered by removing adapter and low-quality sequences, which included sequences with high percentages of poor base calls (high $\mathrm{N}$ percentages of over $5 \%$ ) and sequences containing more than $20 \%$ nucleotides with Q-values $\leq 10$, where Q-value represents the sequencing quality of a given base. Only clean reads were used in de novo assembly, and read-mapping to the transcriptome. RNA-seq data were de novo assembled using the Trinity software 
package for RNS-seq assembly [44]. Short reads were first assembled into longer (but gapless) contigs, then additional reads were then mapped back to previously assembled contigs, with the length of a paired-end read defined as a frame. Next, contigs were connected to access end sequences that could not be further extended from either end to ultimately produce unigene sequences. Next, unigenes were further analyzed and assembled to obtain maximum length nonredundant unigenes using TGICL clustering software set to a minimum overlap length of $100 \mathrm{bp}$. Assembled genes were functionally aligned against the following public databases: KEGG (Kyoto Encyclopedia of Genes and Genomes) and GO (Gene Ontology).

\section{Conclusions}

Expression of ThTrx 5 and associated protein ThTrx can significantly improve plant salt tolerance. During salt stress, ThTrx5 interacts with BAS1 to regulate biological and metabolic pathways involving genes encoding redox processes, hormone signaling pathways, and transcription factors to improve salt tolerance of plants.

Supplementary Materials: The following are available online at http://www.mdpi.com/1422-0067/21/3/1165/s1.

Author Contributions: Conceptualization, J.J.; Methodology, X.S.; Software, J.D.; Writing—original draft, J.L.; Writing - review \& editing, H.L. All authors have read and agreed to the published version of the manuscript.

Funding: This work was supported by the Innovation Project of State Key Laboratory of Tree Genetics and Breeding (Northeast Forestry University) (2015B01), Provincial Funding for Major National Science and Technology Projects and Key R\&D Projects in Heilongjiang Province (GX18B027), and the 111 Project (B16010), Heilongjiang Touyan Innovation Team Program (Tree Genetics and Breeding Innovation Team).

Conflicts of Interest: The authors declare that the research was conducted in the absence of any commercial or financial relationships that could be construed as, or have the appearance of being, a potential conflict of interest.

\section{Abbreviations}

$\begin{array}{ll}\text { BLAST } & \text { the Basic Local Alignment Search Tool } \\ \text { DEGs } & \text { differentially expressed genes } \\ \text { GO } & \text { Gene ontology } \\ \text { KEGG } & \text { Kyoto Encyclopedia of Genes and Genomes } \\ \text { SwissProt } & \text { Swiss-prot sequence data bases } \\ \text { ORFs } & \text { Open reading frames }\end{array}$

\section{References}

1. Wei, L.; Shu, H.X.; Kun, L.P.; Qin, Z.H.; Chao, W.T. Research Progress in Plant Thioredoxin. J. Guizhou Agric. Sci. 2006, 34, 129-131.

2. Meyer, Y.; Buchanan, B.B.; Vignols, F.; Reichheld, J.-P. Thioredoxins and Glutaredoxins: Unifying Elements in Redox Biology. Annu. Rev. Genet. 2009, 43, 335-367. [CrossRef] [PubMed]

3. Michelet, L.; Zaffagnini, M.; Morisse, S.; Sparla, F.; Pérez-Pérez, M.E.; Francia, F.; Danon, A.; Marchand, C.H.; Fermani, S.; Trost, P.; et al. Redox regulation of the Calvin-Benson cycle: Something old, something new. Front. Plant Sci. 2013, 4, 470. [CrossRef]

4. Buchanan, B.B. The Path to Thioredoxin and Redox Regulation in Chloroplasts. Annu. Rev. Plant Biol. 2016, 67, 1-24. [CrossRef]

5. Shaykholeslam Esfahani, E.; Shahpiri, A. Thioredoxin h isoforms from rice are differentially reduced by NADPH/thioredoxin or GSH/glutaredoxin systems. Int. J. Biol. Macromol. 2015, 74, 243-248. [CrossRef]

6. Gelhaye, E.; Rouhier, N.; Navrot, N.; Jacquot, J.-P. The plant thioredoxin system. Cell. Mol. Life Sci. 2005, 62, 24-35. [CrossRef]

7. Mouaheb, N.; Thomas, M.; Verdoucq, L.; Monfort, P.; Meyer, Y. In vivo functional discrimination between plant thioredoxins by heterologous expression in the yeast Saccharomyces cerevisiae. Proc. Natl. Acad. Sci. USA 1998, 95, 3312-3317. [CrossRef] 
8. Murata, Y.; Pei, Z.M.; Mori, I.C.; Schroeder, J. Abscisic Acid Activation of Plasma Membrane Ca ${ }^{2+} \mathrm{Channels}$ in Guard Cells Requires Cytosolic NAD(P)H and Is Differentially Disrupted Upstream and Downstream of Reactive Oxygen Species Production in abi1-1 and abi2-1 Protein Phosphatase 2C Mutants. Plant Cell 2001, 13, 2513-2523. [CrossRef]

9. Gilbert, H.F. Molecular and cellular aspects of thiol-disulfide exchange. Adv. Enzymol. Relat. Areas Mol. Boil. 1990, 63, 69-172.

10. Jaeger, T.; Flohé, L. The thiol-based redox networks of pathogens: Unexploited targets in the search for new drugs. BioFactors 2006, 27, 109-120. [CrossRef]

11. Laloi, C.; Rayapuram, N.; Chartier, Y.; Grienenberger, J.-M.; Bonnard, G.; Meyer, Y. Identification and characterization of a mitochondrial thioredoxin system in plants. Proc. Natl. Acad. Sci. USA 2001, 98, 14144-14149. [CrossRef]

12. Wang, P.; Liu, J.; Liu, B.; Feng, D.; Da, Q.; Shu, S.; Su, J.; Zhang, Y.; Wang, J.; Wang, H.-B. Evidence for a Role of Chloroplastic m-Type Thioredoxins in the Biogenesis of Photosystem II in Arabidopsis. Plant Physiol. 2013, 163, 1710-1728. [CrossRef] [PubMed]

13. Hui-Yu, L.; Kun, N.; Xin, S.; Zi-Jia, W.; Gui-Feng, L.; Jing, J.; Rui-Ping, Z.; Kai-Long, L. Molecular Cloning and Expression Analysis of Nine ThTrx Genes in Tamarix hispida. Plant Mol. Boil. Rep. 2013, 31, 917-924. [CrossRef]

14. Mangelsen, E.; Kilian, J.; Berendzen, K.W.; Kolukisaoglu, Ü.H.; Harter, K.; Jansson, C.; Wanke, D. Phylogenetic and comparative gene expression analysis of barley (Hordeum vulgare) WRKY transcription factor family reveals putatively retained functions between monocots and dicots. BMC Genom. 2008, 9, 194. [CrossRef]

15. Kim, Y.-C.; Masutani, H.; Yamaguchi, Y.; Itoh, K.; Yamamoto, M.; Yodoi, J. Hemin-induced Activation of the Thioredoxin Gene by Nrf2. J. Boil. Chem. 2001, 276, 18399-18406. [CrossRef]

16. Kanzok, S.M.; Fechner, A.; Bauer, H.; Ulschmid, J.K.; Müller, H.M.; Botella-Munoz, J.; Schneuwly, S.; Schirmer, R.H.; Becker, K. Substitution of the Thioredoxin System for Glutathione Reduetase in Drosophila melanogaster. Science 2001, 291, 643-645. [CrossRef]

17. Foyer, C.H.; Noctor, G. Managing the cellular redox hub in photosynthetic organismspce. Plant Cell Environ. 2012, 35, 199-201. [CrossRef]

18. Bello, B.; Zhang, X.; Liu, C.; Yang, Z.; Yang, Z.; Wang, Q.; Zhao, G.; Li, F. Cloning of Gossypium hirsutum Sucrose Non-Fermenting 1-Related Protein Kinase 2 Gene (GhSnRK2) and Its Overexpression in Transgenic Arabidopsis Escalates Drought and Low Temperature Tolerance. PLoS ONE 2014, 9, e112269. [CrossRef]

19. Baier, M. Protective Function of Chloroplast 2-Cysteine Peroxiredoxin in Photosynthesis. Evidence from Transgenic Arabidopsis. Plant Physiol. 1999, 119, 1407-1414. [CrossRef]

20. Baier, M.; Noctor, G.; Foyer, C.H.; Dietz, K.-J. Antisense suppression of 2-Cys peroxiredoxin in Arabidopsis specifically enhances the activities and expression of enzymes associated with ascorbate metabolism but not glutathione metabolism. Plant Physiol. 2000, 124, 823-832. [CrossRef]

21. Baier, M.; Dietz, K.-J. The plant 2-Cys peroxiredoxin BAS1 is a nuclear-encoded chloroplast protein: Its expressional regulation, phylogenetic origin, and implications for its specific physiological function in plants. Plant J. 1997, 12, 179-190. [CrossRef]

22. König, J.; Baier, M.; Horling, F.; Kahmann, U.; Harris, G.; Schürmann, P.; Dietz, K.-J. The plant-specific function of 2-Cys peroxiredoxin-mediated detoxification of peroxides in the redox-hierarchy of photosynthetic electron flux. Proc. Natl. Acad. Sci. USA 2002, 99, 5738-5743. [CrossRef]

23. König, J.; Lotte, K.; Plessow, R.; Brockhinke, A.; Baier, M.; Dietz, K.-J. Reaction mechanism of the 2-Cys peroxiredoxin: Role of the C-terminus and the quarternary structure. Biol. Chem. 2003, 278, 24409-24420. [CrossRef]

24. Baier, M.; Stroher, E.; Karl-Josef, D. The Acceptor Availability at Photosystem I and ABA Control Nuclear Expression of 2-Cys Peroxiredoxin-A in Arabidopsis thaliana. Plant Cell Physiol. 2004, 45, 997. [CrossRef]

25. Nonn, L.; Berggren, M.; Powis, G. Increased Expression of Mitochondrial Peroxiredoxin-3 (Thioredoxin Peroxidase-2) Protects Cancer Cells against Hypoxia and Drug-Induced Hydrogen Peroxide-Dependent Apoptosis11CA52995 and CA772049. Mol. Cancer Res. 2003, 1, 682-689.

26. Tartaglia, L.A.; Storz, G.; Brodsky, M.H.; Lai, A.; Ames, B.N. Alkyl hydroperoxide reductase from Salmonella typhimurium. Sequence and homology to thioredoxin reductase and other flavoprotein disulfide oxidoreductases. J. Boil. Chem. 1990, 265, 10535-10540. 
27. Chae, H.Z.; Chung, S.J.; Rhee, S.G. Thioredoxin-Dependent Peroxide Reductase from Yeast. J. Boil. Chem. 1994, 269, 27670-27678.

28. Pillai, M.A.; Lihuang, Z.; Akiyama, T. Molecular cloning, characterization, expression and chromosomal location of OsGAPDH, a submergence responsive gene in rice (Oryza sativa L.). Theor. Appl. Genet. 2002, 105, 34-42. [CrossRef]

29. Chinnusamy, V.; Zhu, J.; Zhu, J.-K. Salt stress signaling and mechanisms of plant salt tolerance. Genet. Eng. 2006, 27, 141-177.

30. Kohli, A.; Sreenivasulu, N.; Lakshmanan, P.; Kumar, P.P. The phytohormone crosstalk paradigm takes center stage in understanding how plants respond to abiotic stresses. Plant Cell Rep. 2013, 32, 945-957. [CrossRef]

31. Dinneny, J.R. A gateway with a guard: How the endodermis regulates growth through hormone signaling. Plant Sci. 2014, 214, 14-19. [CrossRef] [PubMed]

32. Kariola, T.; Brader, G.; Helenius, E.; Li, J.; Heino, P.; Palva, E.T. Early Responsive To Dehydration 15, a Negative Regulator of Abscisic Acid Responses in Arabidopsis1. Plant Physiol. 2006, 142, 1559-1573. [CrossRef]

33. Kazan, K. Diverse roles of jasmonates and ethylene in abiotic stress tolerance. Trends Plant Sci. 2015, 20, 219-229. [CrossRef] [PubMed]

34. Mahajan, S.; Tuteja, N. Cold, salinity and drought stresses: An overview. Arch. Biochem. Biophys. 2005, 444, 139-158. [CrossRef] [PubMed]

35. Liu, W.; Ji, S.; Fang, X.; Wang, Q.; Li, Z.; Yao, F.; Hou, L.; Dai, S. Protein Kinase LTRPK1 Influences Cold Adaptation and Microtubule Stability in Rice. J. Plant Growth Regul. 2013, 32, 483-490. [CrossRef]

36. Nakashima, K.; Takasaki, H.; Mizoi, J.; Shinozaki, K.; Yamaguchi-Shinozaki, K. NAC transcription factors in plant abiotic stress responses. Biochim. Biophys. Acta (BBA) 2012, 1819, 97-103. [CrossRef]

37. Wang, Y.X. Characterization of a novel Medicago sativa NAC transcription factor gene involved in response to drought stress. Mol. Biol. Rep. 2013, 40, 6451-6458. [CrossRef]

38. Niu, Y.; Figueroa, P.; Browse, J. Characterization of JAZ-interacting bHLH transcription factors that regulate jasmonate responses in Arabidopsis. J. Exp. Bot. 2011, 62, 2143-2154. [CrossRef]

39. Jin, P.; Huang, L.; Wang, D.; Wu, H.; Zhu, L.; Fu, B. Expression profiling of rice AP2/EREBP genes responsive to abiotic stresses. Sci. Agric. Sin. 2009, 42, 3765-3773.

40. Zhou, Q.Y.; Tian, A.G.; Zou, H.F.; Xie, Z.M.; Lei, G.; Huang, J.; Wang, C.M.; Wang, H.W.; Zhang, J.S.; Chen, S.Y. Soybean WRKY-type transcription factor genes, GmWRKY13, GmWRKY21, and GmWRKY54, confer differential tolerance to abiotic stresses in transgenic Arabidopsis plants. Plant Biotechnol. J. 2010, 6, 486-503. [CrossRef]

41. Marker, A.F.H. The use of acetone and methanol in the estimation of chlorophyll in the presence of phaeophytin. Freshw. Boil. 1972, 2, 361-385. [CrossRef]

42. Gambino, G.; Perrone, I.; Gribaudo, I. A Rapid and effective method for RNA extraction from different tissues of grapevine and other woody plants. Phytochem. Anal. 2008, 19, 520-525. [CrossRef] [PubMed]

43. Clough, S.J.; Bent, A.F. Floral dip: A simplified method for Agrobacterium-mediated transformation of Arabidopsis thaliana. Plant J. 1998, 16, 735-743. [CrossRef] [PubMed]

44. Grabherr, M.G.; Haas, B.J.; Yassour, M.; Levin, J.Z.; Thompson, D.A.; Amit, I.; Adiconis, X.; Fan, L.; Raychowdhury, R.; Zeng, Q.; et al. Full-length transcriptome assembly from RNA-Seq data without a reference genome. Nat. Biotechnol. 2011, 29, 644-652. [CrossRef] [PubMed]

(C) 2020 by the authors. Licensee MDPI, Basel, Switzerland. This article is an open access article distributed under the terms and conditions of the Creative Commons Attribution (CC BY) license (http://creativecommons.org/licenses/by/4.0/). 